\title{
CAVEAT EMPTOR- BUYING THE STALE COIN: A CASE STUDY OF BHATT'S ASSOCIATE, INDIA
}

\author{
G. V. Satya Sekhar \\ MBA, Ph.D, Associate Professor, Gitam University, \\ Visakhapatnam- 530045, Andhra Pradesh. India \\ vssg17@gmail.com
}

\begin{abstract}
Several Fintech scams are revealed and throwing challenge to digitalization of financial transactions, such mobile tacking, password hacking, fake mobile wallets, fake web page for online money frauds, fake 'sim-swap' calls, misleading mails and phone calls, cloning of debit and credit cards, e-card skimmer, ATM skimmer.....the list is not ending. Hence, Fintech should be protected with Regtech. Crypto-currency is a recent buzz word and bitcoin, altcoin, litecon etc are tools used to business transactions including fraudulent finance activities. In this context, this case is to explore background of stale coins (I mean, crypto currency) and the scandal activity done by Bhatt's Associate, India.
\end{abstract}

Keywords: Bitcoins, Crypto Currency, Altcoins, Financial Scams, Fintech,

\section{INTRODUCTION}

Digital finance also has an important role to play for small businesses. It not only provides them with access to financing but also to electronic payment systems, secure financial products and a chance to build a financial history. Arjuna Costa, partner of Omidyar Network, underscored the importance of digital finance in terms of building the credit history and transactional data of individuals and firms for lenders.

A report from the McKinsey Global Institute (MGI), Digital finance for all: Powering inclusive growth in emerging economies is the first attempt to quantify the full impact of digital finance. In addition to extensive economic modeling, the report draws on the findings of field visits to seven countries-Brazil, China, Ethiopia, India, 
Prestige International Journal of Management \& IT-Sanchayan, Vol. 8 (2), 2019, pp. 103-107, ISSN : 2277-1689 (Print), 2278 - 8441 (Online)

Mexico, Nigeria, and Pakistan - and more than 150 expert interviews.

According to Bloomberg, Aug $10^{\text {th }}, 2018$, the biggest financial scandal was revealed. This case is about crypto trading in the state of Gujarat, India. It was alleged that investors' poured cash in to a bit-coin based ponzi scheme that exceed the largest banking scandal.

Rajesh Kurup(2017) states that the Indian exchanges of the digital money are gearing up to launch bitcoin futures; but first, they want to integrate other cryptocurrencies such as Ethereum, Ripple and Bitcoin Cash (BCH) on their platform. Other than bitcoins, there are about 1,000 alternative coins (altcoins) in the global market, with Ethereum being the most popular. Altcoins are crypto-currencies that were launched after the success of bitcoin. In India, bitcoins have been available since 2012, and now have 8-9 trading platforms and over a million users.

Many Indians are trading in altcoins due to their higher volatility. Right now, people buy bitcoins from Indian exchanges and then convert them into other crypto-currencies from international exchanges.

\section{RESERVE BANK OF INDIA (RBI) REGULATION}

RBI has repeatedly cautioned users, holders and traders of virtual currencies, including Bitcoins, regarding various risks associated in dealing with such virtual currencies. In view of the associated risks, it has been decided that, with immediate effect, entities regulated by RBI shall not deal with or provide services to any individual or business entities dealing with or settling venture capitalists. However RBI is going to study the possibility of launching non-mineable bit coins.

Experts feel the RBI order will either completely shut down crypto-exchanges such as Zebpay, Unocoin, Coinex and Bitcoin India among 55 others, or they might trade using different cryptos: a user might buy bitcoin in exchange for other altcoins like litecoin or ripple.

\section{A \$3 BILLION SCAM -PONZI SCHEME FOR TAX EVASION: STUDY OF BHATT'S ASSOCIATE, INDIA}

The following is the storyline extracted from published in news papers:

Investigators across Gujarat and in the Indian capital of New Delhi say complaints about crypto frauds began pouring in after the U.S. cease-and-desist letters. Still, those who had been trying to hide untaxed cash were in a quandary. If they went to the authorities, they would have to declare their investments. Crypto chatrooms around the world soon were abuzz about a surge in demand from Indians who were paying a 25 percent premium for bitcoin. Amid the ensuing market turmoil, 
the Reserve Bank of India announced measures that virtually banned crypto transactions. Cryptocurrency exchanges responded with a lawsuit that is due to resume hearings in the Supreme Court in September. Surat, the heart of the scandal, is famed for its entrepreneurial merchants who travel the world to set up a "dhandha," or family business. Their tight-knit communities dominate Antwerp's diamond trade and own a quarter of U.S. motels.

The ingredients are part of an investigation in Gujarat state into allegations that investors poured cash into a bitcoin-based Ponzi scheme that could exceed the country's largest banking scandal.

It began in February, 2017, when property developer Shailesh Bhatt charged into the Home Minister's office in Gujarat, claiming he had been kidnapped by a group of policemen and told to pay 200 bitcoin, worth some $\$ 1.8$ million at the time, for his release. He said he had nowhere else to go.

Between late 2016 and early 2017, Bhatt invested in BitConnect, a cryptocurrency firm that was being promoted in Gujarat by a man called Satish Kumbhani, according to Bhatia, the CID investigator, in an interview at his office late June.

Kumbhani is one of the founders of BitConnect, which has allegedly scammed individuals across the globe, according to Crypto Watchdogs, a group of six investors who've filed a U.S. federal lawsuit against the company. The firm recruited clients worldwide to deposit bitcoin and receive BitConnect coins they could lend at interest rates of more than 40 percent a month. The interest they earned was higher if they recruited others to invest. Attempts to contact the company and Kumbhani for comment were unsuccessful.

As the price of bitcoin soared last year from less than $\$ 1,000$ to more than $\$ 19,700$, so did BitConnect's value. Bhatt and other investors poured bitcoin worth $\$ 3.2$ billion into Bitconnect, according to Bhatia.

The vast inflows from Indian investors were partly the result of government's shock move in November 2016 to invalidate banknotes worth 15 trillion rupees in an effort to curb tax evasion, according to a chartered accountant in Gujarat. As a result of this demonetization, about 45 billion rupees (\$650 million) flowed to Gujarat's port city of Surat, to be hidden away in assets including cryptocurrencies, said the accountant, who asked not to be identified because his clients include some of the city's biggest diamond and textile traders.

"After demonetization, we were watching India," said Kiran Vaidya, a product manager at Toronto-based U.Cash and a blockchain adviser to Canadian banks. "We'd seen how bitcoin rose after the Greece economic crisis and similarly after things went south in Venezuela. The volumes were so high that it was obviously people who had the capacity to move markets." 
Prestige International Journal of Management E IT-Sanchayan, Vol. 8 (2), 2019, pp. 103-107, ISSN : $2277-1689$ (Print), $2278-8441$ (Online)

While the initial rush may have been black money, there were cases of people selling houses and cars in hopes of doubling their investment, said the CID's Bhatia. Then, on Jan. 4, 2018, the state of Texas filed a cease-and-desist order against BitConnect. North Carolina followed five days later. The news came as the price of bitcoin crashed.

Bhatt and nine accomplices including Paladiya kidnapped two BitConnect representatives in Surat and demanded 2,256 bitcoin as ransom, CID investigators alleged. Paladiya, however, wanted more. He contacted his influential uncle, Kotadiya, and tapped the latter's network in the local police to double-cross Bhatt and allegedly extort his bitcoin, according to allegations in police documents and interviews with investigators.

They were confident of success, gambling that Bhatt wouldn't go to the authorities and certain that the anonymity of bitcoin would make the heist untraceable, according to the investigators. They were wrong. Bhatt pressed charges. Bhatt himself has gone "underground" for hiding to avoid arrest because his appeal for bail was rejected, said his lawyer Rupesh Rupareliya.

In a telephone interview, Rupareliya said Bhatt denies any wrongdoing and says that Paladiya handled all the bitcoin transfers as Bhatt wasn't tech savvy. Paladiya's lawyer Yogesh Ravani denied any wrongdoing by his client and said Paladiya was a victim of the kidnappers.

Paladiya is now in jail, facing charges of abduction and extortion, and Bhatt and Kotadiya are both absconding, according to police. Kotadiya posted a video via Whatsapp in April denying wrongdoing and saying he'd informed authorities about the crypto scam, said Prashant Dayal, a senior Gujarati journalist who broke the story.

In the video, reposted on Youtube, Kotadiya says Bhatt is responsible for the scam and threatens to release evidence that could implicate other politicians. Both Bhatt and Paladiya have denied wrongdoing, according to their lawyers.

Shailesh Kumar, Asia director with political risk advisory Eurasia Group, said the alleged scam follows a string of high-profile frauds. "If more names of politicians do come out, there could be a price to pay," he said. "The government will have to find the absconders and bring them back."

The state's elite Criminal Investigation Department was called in and the evidence it has uncovered points to a potential fraud on an epic scale. Eight policemen have been indicted and suspended pending trial. The abduction was allegedly spearheaded by Bhatt's associate, Kirit Paladiya, and masterminded by Paladiya's uncle Nalin Kotadiya, according to Ashish Bhatia, the lead CID investigator. Bhatt has been charged too, as the allegations of kidnapping widened. 


\section{CAVEAT EMPTOR}

One should remember the famous Latin term 'Caveat Emptor'. If the buyer is purchasing stale coin through crypto currency-trading, he will lose money and credibility.

\section{QUESTIONS FOR DISCUSSION}

- Why crypto currency is popular? What are the legal implications are underlying in international business transactions?

- What happens if bitcoins are legally accepted by Reserve Bank of India?

- To whom you support- Bhatt or Paladiya? Give reasons. 